\title{
Impact of preoperative and postoperative membranous urethral length measured by 3 Tesla magnetic resonance imaging on urinary continence recovery after robotic-assisted radical prostatectomy
}

\author{
Wan Song, MD; Chan Kyo Kim, MD;' Byung Kwan Park, MD;2 Hwang Gyun Jeon, MD;1 \\ Byong Chang Jeong, MD; Seong II Seo, MD; Seong Soo Jeon, MD;' Han Yong Choi, MD;' Hyun Moo Lee, MD'
}

'Department of Urology, Samsung Medical Centre, Sungkyunkwan University School of Medicine, Seoul, Korea; ${ }^{2}$ Department of Radiology and Centre for Imaging Science, Samsung Medical Centre, Sungkyunkwan University School of Medicine, Seoul, Korea

Cite as: Can Urol Assoc J 2017;11(3-4):E93-9. http://dx.doi.org/10.5489/cuaj.4035 Published online March 16, 2017

\section{Abstract}

Introduction: We sought to investigate the impact of preoperative and postoperative membranous urethral length (MUL) on urinary continence using 3 Tesla (3T) magnetic resonance imaging (MRI) after robotic-assisted radical prostatectomy (RARP).

Methods: Between 2008 and 2013, 190 men with RARP underwent preoperative and postoperative MRI. Patients who received adjuvant radiotherapy or who were lost to followup were excluded, leaving 186 patients eligible for analysis. Preoperative MUL was estimated from the prostate apex to the penile bulb, while postoperative MUL was estimated from the bladder neck to penile bulb. Patients with no pads or protection were considered to have complete continence. Logistic regression analysis was used to identify predictors associated with urinary incontinence at six and 12 months.

Results: Age was commonly associated with urinary incontinence at six and 12 months. In addition, diabetes mellitus (DM) was another factor associated with urinary incontinence at 12 months. When adjusting these variables, preoperative MUL $\leq 16 \mathrm{~mm}(95 \%$ confidence interval $[\mathrm{Cl}] 1.01-1.14 ; \mathrm{p}=0.022)$, postoperative MUL $\leq 14 \mathrm{~mm}(95 \% \mathrm{Cl} 1.16-9.80 ; \mathrm{p}=0.025)$ and percent change of MUL $>18 \%(95 \% \mathrm{Cl} 1.17-7.23 ; \mathrm{p}=0.021)$ were significantly associated with urinary incontinence at six months. However, at 12 months, preoperative MUL $\leq 13.5 \mathrm{~mm}(95 \% \mathrm{Cl} 1.85-19.21 ; \mathrm{p}=0.003)$ and postoperative MUL $\leq 13 \mathrm{~mm}(95 \% \mathrm{Cl} 1.24-13.84 ; p=0.021)$ had impacts on urinary incontinence, but not percent change of MUL. Conclusions: Preoperative and postoperative MUL were significantly associated with urinary continence recovery after RARP. Therefore, efforts to preserve MUL are highly recommended during surgery for optimal continence outcomes after RARP.

\section{Introduction}

Advances in robotic technology have enabled wide adoption of robotic-assisted radical prostatectomy (RARP) for treat- ment of prostate cancer. ${ }^{1,2}$ Patel et al proposed ideal outcomes of RARP, called the "pentafecta," with the following criteria: concurrent achievement of urinary continence, sexual potency, no evidence of biochemical recurrence or postoperative complications, and negative surgical margins..$^{3,4}$ Of these factors, failure to achieve urinary continence after RARP is a major concern because it has a negative effect on quality of life and can cause psychological problems, such as anxiety or depression. ${ }^{5}$ It is reported that approximately $4-22 \%$ of patients do not achieve urinary continence 12 months after RARP. ${ }^{4,6-9}$

Recent studies reported that preoperative clinical factors, anatomical characteristics, and surgical techniques are significantly associated with urinary incontinence after RARP. ${ }^{1,7,10-15}$ Of these factors, membranous urethral length (MUL) is an important factor that directly correlates with the functional sphincter mechanism. The urethral sphincter mechanism is composed of an external striated sphincter and an internal smooth muscle layer that are both crucial to maintaining urethral closure pressure..$^{15}$ Preservation of maximal MUL is necessary to regain urinary continence, but it is affected by clinical factors, surgeon experience, and surgical technique.

The development of imaging modalities, such as magnetic resonance imaging (MRI) has enabled more accurate understanding of anatomical structure in the urethra. Previous studies showed that preservation of MUL is correlated with urinary continence after open or laparoscopic radical prostatectomy, and also demonstrated preoperative MUL as a significant predictor for recovery of urinary continence. ${ }^{10,11,16}$ However, the roles of postoperative MUL, in addition to preoperative MUL and perioperative change in MUL with RARP have not been fully investigated. Therefore, we investigated the impact of preoperative and postoperative MUL measured with 3 Tesla (3T) MRI on urinary continence recovery after RARP. 


\section{Methods}

\section{Patient population}

After receiving study approval from the institutional review board, prospectively maintained databases of 1332 patients who underwent RARP for prostate cancer between June 2008 and December 2013 were retrospectively reviewed. In our hospital, preoperative prostate MRI was routinely performed to assess local stage. A total of 190 patients who also underwent postoperative prostate MRI were identified. Three patients were excluded because they received adjuvant radiation therapy before postoperative prostate MRI and one patient was excluded for followup less than one year. No patients had evidence of local recurrence on postoperative prostate $\mathrm{MRI}$ and no patients received salvage radiation therapy. The mean time from preoperative prostate $\mathrm{MRI}$ to postoperative prostate MRI was 12.6 months.

\section{Clinicopathological parameters}

Patient demographics (age, height, weight), medical comorbidities, perioperative parameters (nerve preservation, operation time, estimated blood loss), and postoperative parameters (pathological stage, pathological Gleason score, positive surgical margin) were reviewed. Using a questionnaire during followup, patients reported urinary continence at one month, three months, six months, and 12 months after RARP. A five-point scale was used to assess continence grade. ${ }^{11}$ Patients with Level 1 urinary continence (no pads or protection) were considered to have complete continence.

MUL was estimated in the midline sagittal plane crossreferenced to the coronal plane on T2-weight images (Fig.

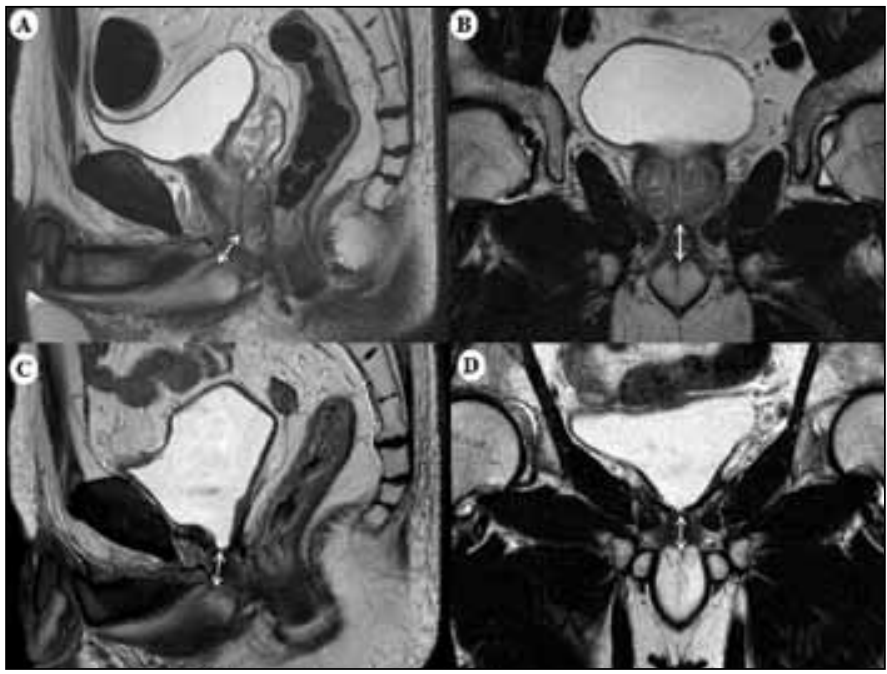

Fig. 1. Preoperative membranous urethral length measured in the $(\boldsymbol{A})$ sagittal and $(\boldsymbol{B})$ coronal planes, and postoperative membranous urethral length measured in the $(\boldsymbol{C})$ sagittal and $(\boldsymbol{D})$ coronal planes from T2-weighted magnetic resonance imaging.
1). On preoperative MRI, MUL was defined as a distance from the apex of prostate to the urethra at the level of the penile bulb (Figs. 1A, 1B). On postoperative MRI, MUL was defined as a distance from the bladder neck to the urethra at the level of the penile bulb (Figs. 1C, 1D). The percent change of MUL was calculated by dividing the difference between preoperative and postoperative MUL by preoperative MUL.

\section{Statistical analysis}

Continuous variables were expressed as mean (standard deviation, range) and were compared using the independent t-test. Categorical variables were shown as absolute values (percentage) and compared using the chi-squared test or Fisher's exact test. Univariate and multivariate logistic regression analyses were performed to determine predictive factors associated with urinary incontinence six months and 12 months after RARP. To further evaluate the impact of preoperative, postoperative, and percent change of MUL on urinary continence, multivariate logistic regression analyses were employed with adjustment of the variables (age at six months, age and diabetes mellitus [DM] at 12 months) associated with urinary incontinence after RARP. All statistical analyses were performed using IBM SPSS version 20.0 (IBM Corp. Armonk, NY, U.S.). Two-sided pvalues $<0.05$ were considered statistically significant.

\section{Results}

The baseline clinical and pathological characteristics of 186 patients who underwent RARP are summarized in Table 1. At 12 months after RARP, urinary continence was restored in $165(88.7 \%)$ patients. When patients were divided into two groups (continence (+) versus continence (-)) according to urinary continence 12 months after RARP, mean age at surgery (64.0 vs. 68.5 years), preoperative MUL (15.9 vs. $14.9 \mathrm{~mm}$ ), and postoperative MUL (13.9 vs. $13.0 \mathrm{~mm}$ ) were significantly different (each $\mathrm{p}<0.05$ ).

Serial changes in urinary continence recovery after RARP are depicted in Fig. 2. Of 21 patients who remained incontinent after 12 months, anticholinergic agents or functional electrical stimulation with biofeedback were used to treat 18 patients. Anti-incontinence surgeries were performed for three patients with continued urinary incontinence (artificial urinary sphincter in two patients and suburethral tension adjustable sling [REMEEX system] in one patient).

Logistic regression analysis was used to identify prognostic factors for urinary incontinence at six months and 12 months after RARP, and the results are summarized in Table 2. On multivariate analysis, only age $(95 \%$ confidence interval $[\mathrm{Cl}]$ 1.01-1.14; $p=0.022$ ) was associated with urinary incontinence at six months, while both age (95\% Cl 1.02-1.23; 


\begin{tabular}{|c|c|c|c|c|}
\hline \multirow{2}{*}{ Variables } & \multirow[t]{2}{*}{ Total } & \multicolumn{2}{|c|}{ At 12 months after RARP } & \multirow[t]{2}{*}{$\mathbf{p}$} \\
\hline & & Continence (+) & Continence (-) & \\
\hline No. of patients & 186 & 165 & 21 & \\
\hline Age at surgery, years & $64.5 \pm 7.6(65.0,38.0-79.0)$ & $64.0 \pm 7.7(65.0,38.0-78.0)$ & $68.5 \pm 6.0(69.0,56.0-79.0)$ & 0.013 \\
\hline Preoperative PSA, ng/ml & $\begin{array}{c}8.25 \pm 9.11 \\
(6.30,1.35-83.50)\end{array}$ & $\begin{array}{c}8.18 \pm 9.25 \\
(6.07,1.35-83.50)\end{array}$ & $\begin{array}{c}8.77 \pm 8.12 \\
(6.50,2.36-38.60)\end{array}$ & 0.583 \\
\hline Diabetes mellitus & $31(16.7)$ & $24(14.5)$ & $7(33.3)$ & $0.055^{*}$ \\
\hline Hypertension & $72(38.7)$ & $60(36.4)$ & $12(57.1)$ & 0.066 \\
\hline $\mathrm{BMI}, \mathrm{kg} / \mathrm{m}^{2}$ & $24.5 \pm 2.9(24.2,16.0-35.1)$ & $24.4 \pm 2.9(24.2,16.0-35.1)$ & $25.3 \pm 2.3(25.4,21.8-30.0)$ & 0.148 \\
\hline Prostate volume, radiologic, $\mathrm{ml}$ & $34.0 \pm 15.9(30.0,8.0-113.0)$ & $33.8 \pm 15.7(30.0,8.0-113.0)$ & $35.3 \pm 17.4(28.0,15.0-72.0)$ & 0.991 \\
\hline ASA score & & & & $0.070 *$ \\
\hline 1 & $49(26.3)$ & $47(28.5)$ & $2(9.5)$ & \\
\hline $2-3$ & $137(73.7)$ & $118(71.5)$ & $19(90.5)$ & \\
\hline \multicolumn{5}{|l|}{ Operative findings } \\
\hline Nerve preservation & & & & 0.729 \\
\hline None or unilateral & $82(44.1)$ & $72(43.6)$ & $10(47.6)$ & \\
\hline Bilateral & $104(55.9)$ & $93(56.4)$ & $11(52.4)$ & \\
\hline Operation time, $\min$ & $\begin{array}{c}294.5 \pm 88.9 \\
(298.0,96.0-600.0)\end{array}$ & $\begin{array}{c}292.2 \pm 86.9 \\
(298.0,96.0-600.0)\end{array}$ & $\begin{array}{c}312.6 \pm 104.6 \\
(290.0,120.0-515.0)\end{array}$ & 0.507 \\
\hline $\mathrm{EBL}, \mathrm{ml}$ & $\begin{array}{c}304.9 \pm 217.5 \\
(250.0,30.0-1800.0)\end{array}$ & $\begin{array}{c}299.8 \pm 214.5 \\
(250.0,30.0-1800.0)\end{array}$ & $\begin{array}{c}344.8 \pm 241.6 \\
(300.0,100.0-1000.0)\end{array}$ & 0.514 \\
\hline \multicolumn{5}{|l|}{ Pathological findings } \\
\hline \multicolumn{5}{|l|}{ Gleason score } \\
\hline$\leq 6$ & $33(17.7)$ & $33(20.0)$ & $3(14.3)$ & \\
\hline 7 & $137(73.7)$ & $119(72.1)$ & $15(71.4)$ & \\
\hline$\geq 8$ & $16(8.6)$ & $13(7.9)$ & $3(14.3)$ & \\
\hline Extracapsular extension & & & & 0.583 \\
\hline Yes & $41(22.0)$ & $31(18.8)$ & $5(23.8)$ & \\
\hline No & $145(78.0)$ & $134(81.2)$ & $16(76.2)$ & \\
\hline Seminal vesicle invasion & & & & $0.180^{*}$ \\
\hline Yes & 7 ( 3.8) & $5(3.0)$ & $2(9.5)$ & \\
\hline No & $179(96.2)$ & $160(97.0)$ & 19 (90.5) & \\
\hline Positive surgical margin & & & & $0.266^{*}$ \\
\hline Yes & $21(11.3)$ & $17(10.3)$ & $4(19.0)$ & \\
\hline No & $165(88.7)$ & $148(89.7)$ & $17(81.0)$ & \\
\hline \multicolumn{5}{|c|}{ Membranous urethral length, $\mathrm{mm}$} \\
\hline Preoperative MRI & $15.6 \pm 2.7(15.9,7.2-22.9)$ & $15.9 \pm 2.6(16.1,10.2-22.9)$ & $13.9 \pm 2.9(13.5,7.2-19.0)$ & 0.004 \\
\hline Postoperative MRI & $14.7 \pm 2.7(14.9,6.3-22.8)$ & $14.9 \pm 2.5(15.1,8.8-22.8)$ & $13.0 \pm 3.3(13.8,6.3-18.0)$ & 0.015 \\
\hline
\end{tabular}

$\mathrm{p}=0.017)$ and $\mathrm{DM}(95 \% \mathrm{Cl} 1.03-12.74 ; \mathrm{p}=0.046)$ were associated with urinary incontinence at 12 months.

The impact of preoperative and postoperative MUL measured by MRI on urinary incontinence six months and 12 months after RARP is shown in Table 3. On multivariate logistic regression analysis adjusted for age, preoperative MUL $\leq 16 \mathrm{~mm}(95 \% \mathrm{Cl} 1.01-1.14 ; \mathrm{p}=0.022)$, postoperative $\mathrm{MUL} \leq 14 \mathrm{~mm}(95 \% \mathrm{Cl} 1.16-9.80 ; \mathrm{p}=0.025)$ and percent change of MUL $>18 \%(95 \% \mathrm{Cl} 1.17-7.23 ; p=0.021)$ were significantly associated with urinary incontinence at six months. When adjusted for age and DM, preoperative MUL $\leq 13.5 \mathrm{~mm}(95 \% \mathrm{Cl} 1.85-19.21 ; \mathrm{p}=0.003)$ and post- operative MUL $\leq 13$ mm (95\% Cl 1.24-13.84; $p=0.021)$, but not percent change of $\mathrm{MUL}$, were associated with urinary incontinence 12 months after RARP.

\section{Discussion}

In the present study, urinary incontinence was identified in $24.7 \%$ patients at six months and $11.3 \%$ patients at 12 months after RARP. Age was commonly associated with urinary incontinence at six months and 12 months. DM is another important factor that affects urinary continence recovery after RARP. When stratified according to preopera- 


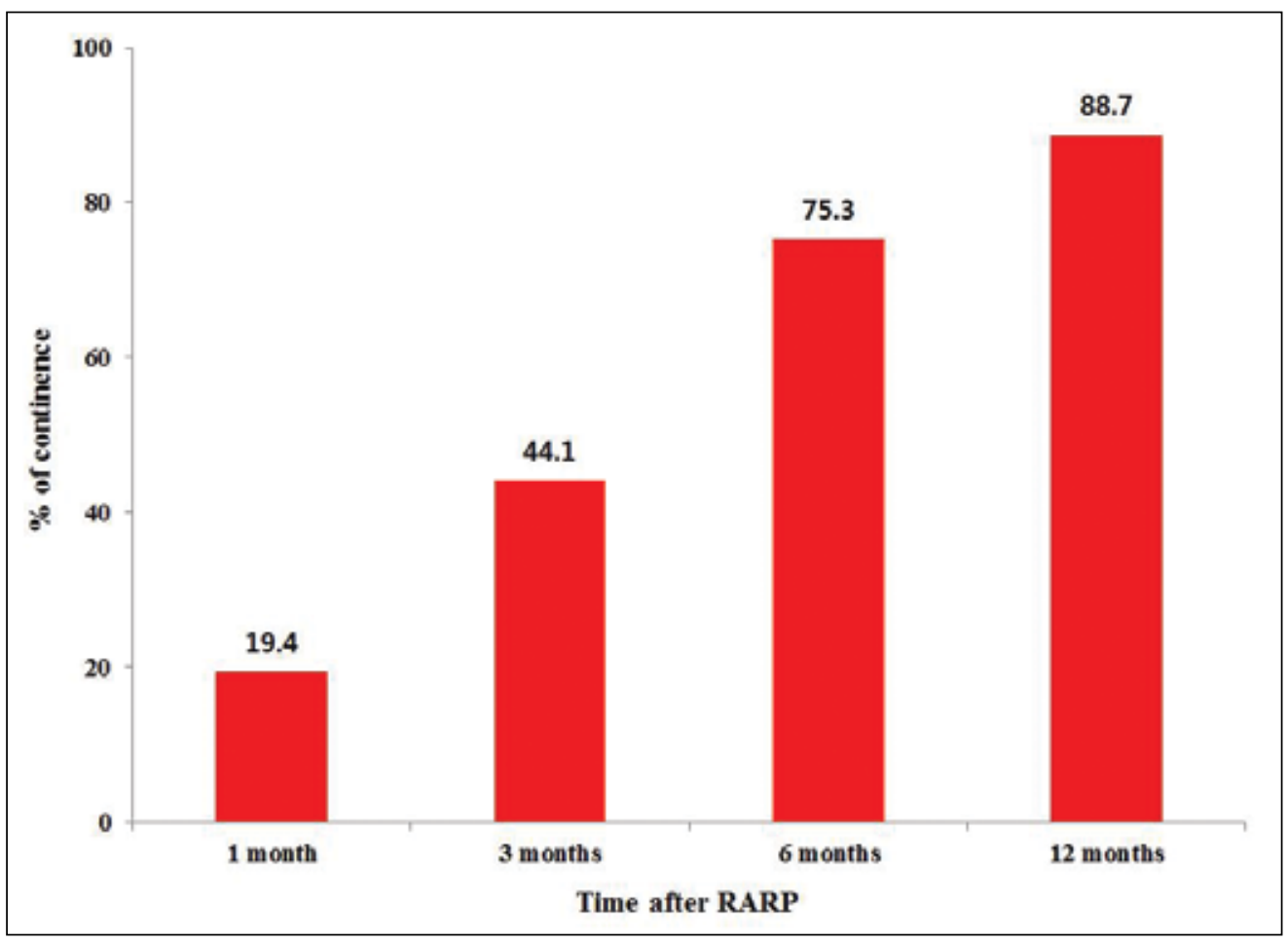

Fig. 2. Serial changes in urinary continence recovery after robotic-assisted radical prostatectomy.
Coakley et $\mathrm{al}^{18}{ }^{18}$ recent studies have showed that preoperative MUL was associated with recovery of continence after radical prostatectomy. ${ }^{13,16,19-21}$ Our study not only confirmed their findings, but also evaluated the relationship between postoperative MUL and urinary continence. Our results showed that postoperative MUL was significantly associated with urinary continence recovery, indicating that residual MUL also influenced recovery of continence. When considering that percent change of MUL $>18 \%$ was significantly associated with urinary incontinence at six months, an effort should be made to preserve maximal MUL to reduce early urinary incontinence during RARP.

In our study, there was a difference in MUL associated with tive and postoperative MUL adjusted by the abovementioned prognostic factors, preoperative $\mathrm{MUL} \leq 16 \mathrm{~mm}$, postoperative MUL $\leq 14 \mathrm{~mm}$, and percent change of MUL $>18 \%$ were significantly associated with urinary incontinence at six months. At 12 months, preoperative MUL $\leq 13.5 \mathrm{~mm}$ and postoperative MUL $\leq 13 \mathrm{~mm}$ had impacts on urinary incontinence, but not percent change of MUL. These results indicated that efforts to preserve MUL are highly recommended during surgery for optimal continence outcomes. To the best of our knowledge, this is the largest study to examine the relationship between both preoperative and postoperative MUL and urinary continence after RARP.

Recent advances in knowledge of pelvic structure have led to increased understanding of the urinary continence mechanism. ${ }^{15}$ In brief, the urethral sphincter system and periurethral support system are two main mechanisms of preserving urinary continence. The external striated sphincter is the main structure maintaining urethral closure pressure greater than bladder pressure. This sphincter is mostly located from the prostate apex to the urethra at the level of the penile bulb. ${ }^{13}$ Dubbelman et al reported that maximal urethral closure pressure decreased approximately $27 \%$ from $89.6 \mathrm{~cm} \mathrm{H}_{2} \mathrm{O}$ preoperatively to $65.2 \mathrm{~cm} \mathrm{H}_{2} \mathrm{O}$ postoperatively. ${ }^{17}$ Therefore, longer MUL values are more likely to maintain sphincter function and detailed manipulation of the prostate apex is recommended to avoid damage to the external striated sphincter.

The development of MRI has enabled more accurate measurement of perioperative MUL. After the first study by urinary incontinence between six months and 12 months after RARP. These results suggest that the restoration of urinary continence could be enhanced with time. A possible explanation for this is the repair over time of the nerve and periurethral ated sphincter is innervated from the pelvic plexus and from dal nerve. ${ }^{15}$ These nerves come into the posterior aspects of the external striated sphincter and are intertwined with the prostatic apex. A median of 12 months is needed to restore function from neuropraxic injury after radical prostatectomy when postulated from the recovery for erectile dysfunction. ${ }^{22}$ Van der Poel et al identified that preservation of the lateral prostatic fascia could protect neurovascular structures that are crucial for improving post-prostatectomy continence. ${ }^{23}$

The development of diagnostic imaging modalities, such as ultrasonography or functional MRI, have helped determine the impact of preoperative and postoperative MUL on urinary continence. ${ }^{24,25}$ In addition to MUL, they could easily visualize the motility of urethra and pelvic wall, bladderurethra angle, and scarring or foreign body of anastomosis site. Moreover, healing of anastomosis site is also important, as iatrogenic sphincter lesion could cause early incontinence after radical prostatectomy. Gerullis et al reported that sphincter injury, such as suture penetration, was identified in patients with early incontinence after surgery. ${ }^{26}$

Our study also showed that DM is an important factor that affects urinary continence recovery at 12 months supporting system damaged during RARP. The external strithe perineal branch and intrapelvic branch of the puden- 
Table 2. Logistic regression analyses for identifying predictive factors for urinary incontinence...

(A) 6 months after RARP

\begin{tabular}{|c|c|c|c|c|c|c|}
\hline \multirow{2}{*}{ Variables } & \multicolumn{3}{|c|}{ Univariate } & \multicolumn{3}{|c|}{ Multivariate } \\
\hline & OR & $95 \% \mathrm{Cl}$ & $\mathbf{p}$ & OR & $95 \% \mathrm{Cl}$ & $\mathbf{p}$ \\
\hline Age $^{*}$ & 1.07 & $1.02-1.12$ & 0.007 & 1.07 & $1.01-1.14$ & 0.022 \\
\hline Preoperative PSA* & 1.01 & $0.98-1.05$ & 0.443 & 1.01 & $0.97-1.04$ & 0.784 \\
\hline Diabetes mellitus (vs. no) & 1.89 & $0.83-4.31$ & 0.133 & 1.92 & $0.79-4.66$ & 0.152 \\
\hline Hypertension (vs. no) & 1.65 & $0.84-3.24$ & 0.145 & 1.08 & $0.49-2.39$ & 0.849 \\
\hline $\mathrm{BMI}^{*}$ & 1.03 & $0.92-1.16$ & 0.604 & 1.04 & $0.91-1.19$ & 0.584 \\
\hline Prostate volume* & 1.01 & $0.99-1.03$ & 0.361 & 1.01 & $0.98-1.03$ & 0.660 \\
\hline ASA score (2-3 vs. 1$)$ & 2.39 & $0.99-5.77$ & 0.053 & 1.98 & $0.69-5.68$ & 0.206 \\
\hline $\begin{array}{l}\text { Nerve-sparing } \\
\quad \text { (Bilateral versus none or unilateral) }\end{array}$ & 0.82 & $0.42-1.60$ & 0.556 & 1.19 & $0.53-2.71$ & 0.672 \\
\hline Operation time* & 1.00 & $0.99-1.00$ & 0.976 & 1.00 & $0.99-1.00$ & 0.832 \\
\hline $\mathrm{EBL}^{*}$ & 1.00 & $0.99-1.00$ & 0.604 & 1.00 & $0.99-1.00$ & 0.920 \\
\hline \multicolumn{7}{|l|}{ Pathological Gleason score } \\
\hline$\leq 6$ & 1.00 & ref & & 1.00 & ref & \\
\hline 7 & 2.07 & $0.74-5.77$ & 0.163 & 1.31 & $0.42-4.11$ & 0.644 \\
\hline$\geq 8$ & 1.87 & $0.43-8.19$ & 0.408 & 0.94 & $0.17-5.28$ & 0.944 \\
\hline Pathological stage ( $\geq \mathrm{T} 3$ vs. $\leq \mathrm{T} 2$ ) & 1.83 & $0.86-3.90$ & 0.117 & 1.78 & $0.77-4.09$ & 0.178 \\
\hline \multicolumn{7}{|l|}{ (B) 12 months after RARP } \\
\hline Age* $^{*}$ & 1.10 & $1.02-1.18$ & 0.013 & 1.12 & $1.02-1.23$ & 0.017 \\
\hline Preoperative PSA* & 1.01 & $0.96-1.05$ & 0.782 & 0.99 & $0.93-1.07$ & 0.884 \\
\hline Diabetes mellitus (vs. no) & 2.94 & $1.08-8.03$ & 0.036 & 3.61 & $1.03-12.74$ & 0.046 \\
\hline Hypertension (vs. no) & 2.33 & $0.93-5.86$ & 0.071 & 1.42 & $0.46-4.40$ & 0.546 \\
\hline $\mathrm{BMI}^{*}$ & 1.10 & $0.94-1.28$ & 0.224 & 1.17 & $0.96-1.43$ & 0.116 \\
\hline Prostate volume* & 1.01 & $0.98-1.03$ & 0.674 & 1.00 & $0.97-1.03$ & 0.930 \\
\hline ASA score (2-3 vs. 1) & 3.78 & $0.85-16.89$ & 0.081 & 2.32 & $0.39-13.83$ & 0.357 \\
\hline $\begin{array}{l}\text { Nerve-sparing } \\
\quad \text { (Bilateral vs. none or unilateral) }\end{array}$ & 0.85 & $0.34-2.12$ & 0.729 & 2.04 & $0.59-7.02$ & 0.260 \\
\hline Operation time* & 1.01 & $1.00-1.01$ & 0.324 & 1.00 & $0.99-1.00$ & 0.777 \\
\hline $\mathrm{EBL}^{*}$ & 1.00 & $0.99-1.00$ & 0.378 & 1.00 & $0.99-1.00$ & 0.908 \\
\hline \multicolumn{7}{|l|}{ Pathological Gleason score } \\
\hline$\leq 6$ & 1.00 & ref & & 1.00 & ref & \\
\hline 7 & 2.07 & $0.74-5.77$ & 0.163 & 1.31 & $0.42-4.11$ & 0.644 \\
\hline$\geq 8$ & 1.87 & $0.43-8.19$ & 0.408 & 0.94 & $0.17-5.28$ & 0.944 \\
\hline Pathological stage ( $\geq \mathrm{T} 3$ vs. $\leq \mathrm{T} 2$ ) & 1.70 & $0.84-3.42$ & 0.139 & 1.39 & $0.62-3.11$ & 0.421 \\
\hline
\end{tabular}

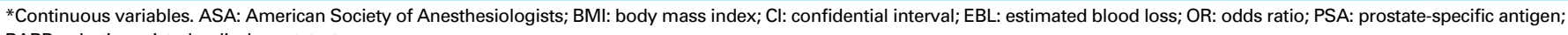
RARP: robotic-assisted radical prostatectomy.

after RARP. In a study by Teber et al, ${ }^{27}$ patients with DM require more time to regain urinary continence than nonDM patients. They demonstrated that patients with DM for more than five years were more likely to experience urinary incontinence than those with DM for less than five years at three, 12, and 24 months postoperatively. They suggested that diabetic nephropathy would not only affect autonomic nerves involved in the external striated sphincter, but also impair bladder function.

Collectively, patients of older age and with DM are more likely not to regain urinary continence until 12 months after RARP. Because both preoperative MUL and postoperative MUL are correlated with urinary incontinence, precise manipulation of the prostatic apex is recommended to preserve the urethral sphincter system during RARP. In patients with preoperative MUL $\leq 13.5 \mathrm{~mm}$ and postoperative MUL $\leq 13 \mathrm{~mm}$, reconstruction and reinforcement of the periurethral support system should be performed, including anterior and posterior reconstruction or total reconstruction. In a study by Nguyen et al, ${ }^{19}$ in patients with short sphincters less than 14 $\mathrm{mm}$, the continence rate was $47 \%$ for the control group at six months, while it was $81 \%$ for those who underwent anterior reconstruction and $90 \%$ for those who underwent total reconstruction. They demonstrated that with reconstruction of the support system, the continence of the short sphincter group did not differ from that of the long sphincter group. 
Table 3. Association of preoperative and postoperative MRI-measured membranous urethral length with urinary incontinence...

(A) 6 months after RARP

\begin{tabular}{|c|c|c|c|c|c|c|}
\hline & \multicolumn{3}{|c|}{ Univariate } & \multicolumn{3}{|c|}{ Age adjusted } \\
\hline & OR & $95 \% \mathrm{Cl}$ & $\mathbf{p}$ & OR & $95 \% \mathrm{Cl}$ & $\mathbf{p}$ \\
\hline $\begin{array}{l}\text { Preoperative membranous urethral length, } \mathrm{mm} \\
\leq 16 \text { vs. }>16\end{array}$ & 3.19 & $1.55-6.58$ & 0.002 & 3.20 & $1.54-6.68$ & 0.002 \\
\hline \multicolumn{7}{|l|}{ Preoperative membranous urethral length, $\mathrm{mm}$} \\
\hline Membranous urethral length $>16$ & 1.00 & ref & & 1.00 & ref & \\
\hline $13.5<$ Membranous urethral length $\leq 16$ & 2.60 & $1.13-5.95$ & 0.024 & 2.71 & $1.16-6.32$ & 0.021 \\
\hline Membranous urethral length $\leq 13.5$ & 4.08 & $1.74-9.56$ & 0.001 & 3.88 & $1.63-9.24$ & 0.002 \\
\hline $\begin{array}{l}\text { Postoperative membranous urethral length, } \mathrm{mm} \\
\leq 15 \text { vs. }>15\end{array}$ & 3.89 & $1.83-8.27$ & $<0.001$ & 3.75 & $1.75-8.07$ & 0.001 \\
\hline \multicolumn{7}{|l|}{ Postoperative membranous urethral length, $\mathrm{mm}$} \\
\hline Membranous urethral length $>15$ & 1.00 & ref & & 1.00 & ref & \\
\hline $14<$ Membranous urethral length $\leq 15$ & 1.91 & $0.63-5.75$ & 0.250 & 1.81 & $0.59-5.54$ & 0.299 \\
\hline $13<$ Membranous urethral length $\leq 14$ & 3.94 & $1.40-11.06$ & 0.009 & 3.37 & $1.16-9.80$ & 0.025 \\
\hline Membranous urethral length $\leq 13$ & 5.60 & $2.36-13.27$ & $<0.001$ & 5.84 & $2.41-14.12$ & $<0.001$ \\
\hline $\begin{array}{l}\text { Percent change of membranous urethral length, } \% \\
>6 \text { vs. } \leq 6\end{array}$ & 1.65 & $0.84-3.25$ & 0.150 & 1.63 & $0.82-3.26$ & 0.167 \\
\hline \multicolumn{7}{|l|}{ Percent change of membranous urethral length, \% } \\
\hline Percent change $\leq 6$ & 1.00 & ref & & 1.00 & ref & \\
\hline $6<$ Percent change $\leq 12$ & 0.89 & $0.32-2.48$ & 0.822 & 0.81 & $0.28-2.29$ & 0.685 \\
\hline $12<$ Percent change $\leq 18$ & 1.50 & $0.60-3.78$ & 0.390 & 1.68 & $0.65-4.36$ & 0.283 \\
\hline Percent change $>18$ & 3.06 & $1.26-7.43$ & 0.014 & 2.94 & $1.17-7.23$ & 0.021 \\
\hline \multicolumn{7}{|l|}{ (B) 12 months after RARP } \\
\hline & \multicolumn{3}{|c|}{ Univariate } & \multicolumn{3}{|c|}{ Multivariate $^{\#}$} \\
\hline & OR & $95 \% \mathrm{Cl}$ & $\mathbf{p}$ & OR & $95 \% \mathrm{Cl}$ & $\mathbf{p}$ \\
\hline $\begin{array}{l}\text { Preoperative membranous urethral length, } \mathrm{mm} \\
\leq 16 \text { vs. }>16\end{array}$ & 2.66 & $0.98-7.18$ & 0.054 & 2.72 & $0.97-7.64$ & 0.057 \\
\hline \multicolumn{7}{|l|}{ Preoperative membranous urethral length, $\mathrm{mm}$} \\
\hline Membranous urethral length $>16$ & 1.00 & ref & & 1.00 & ref & \\
\hline $13.5<$ Membranous urethral length $\leq 16$ & 1.16 & $0.31-4.30$ & 0.828 & 1.10 & $0.28-4.28$ & 0.895 \\
\hline Membranous urethral length $\leq 13.5$ & 5.03 & $1.71-14.75$ & 0.003 & 5.95 & $1.85-19.21$ & 0.003 \\
\hline $\begin{array}{l}\text { Postoperative membranous urethral length, } \mathrm{mm} \\
\leq 15 \text { vs. }>15\end{array}$ & 3.24 & $1.13-9.25$ & 0.028 & 3.10 & $1.05-9.18$ & 0.041 \\
\hline \multicolumn{7}{|l|}{ Postoperative membranous urethral length, $\mathrm{mm}$} \\
\hline Membranous urethral length $>15$ & 1.00 & ref & & 1.00 & ref & \\
\hline $14<$ Membranous urethral length $\leq 15$ & 2.26 & $0.50-10.21$ & 0.288 & 1.96 & $0.40-9.58$ & 0.408 \\
\hline $13<$ Membranous urethral length $\leq 14$ & 2.77 & $0.69-11.12$ & 0.152 & 2.63 & $0.63-10.99$ & 0.185 \\
\hline Membranous urethral length $\leq 13$ & 4.15 & $1.30-13.25$ & 0.016 & 4.15 & $1.24-13.84$ & 0.021 \\
\hline $\begin{array}{l}\text { Percent change of membranous urethral length, } \% \\
>6 \text { vs. } \leq 6\end{array}$ & 1.04 & $0.42-2.57$ & 0.940 & 0.84 & $0.32-2.19$ & 0.716 \\
\hline \multicolumn{7}{|l|}{ Percent change of membranous urethral length, \% } \\
\hline Percent change $\leq 6$ & 1.00 & ref & & 1.00 & ref & \\
\hline $6<$ Percent change $\leq 12$ & 0.80 & $0.21-3.11$ & 0.747 & 0.56 & $0.14-2.34$ & 0.428 \\
\hline $12<$ Percent change $\leq 18$ & 0.80 & $0.21-3.11$ & 0.747 & 0.70 & $0.17-2.92$ & 0.623 \\
\hline Percent change $>18$ & 1.60 & $0.50-5.12$ & 0.429 & 1.35 & $0.40-4.60$ & 0.629 \\
\hline
\end{tabular}

Our study had several important limitations. First, this study had a retrospective design, relatively small size, and was performed by three surgeons, raising the potential for selection bias. However, to our knowledge, this is the largest study to measure both preoperative and postoperative MUL with $3 \mathrm{~T} \mathrm{MRI}$ and evaluate their relationship with urinary continence after RARP. Second, urinary continence status was evaluated based on the number of pads patients used, 
which is relatively subjective. In general, measurement of the 24-hour pad weight is considered the most accurate test. ${ }^{28}$ However, this is not easy to apply in practice, so we measured the severity of urinary incontinence by a self-reported questionnaire that could also reflect self-satisfaction. Finally, because we focused on the impacts of preoperative and postoperative MUL on urinary incontinence, other parameters affecting urinary incontinence might be underestimated.

\section{Conclusion}

Preoperative and postoperative MUL measured with 3T MRI were significantly associated with urinary continence recovery after RARP. These findings suggest that efforts to preserve MUL are highly recommended during surgery for optimal continence outcomes. Further large-scale studies are needed to verify our results for clinical application.

Competing interests: The authors report no competing personal or financial interests.

This paper has been peer-reviewed.

\section{References}

1. Ficarra V, Novara G, Rosen RC, et al. Systematic review and meta-analysis of studies reporting urinary continence recovery after robot-assisted radical prostatectomy. Eur Urol 2012;62:405-17. hitps://doi.org/10.1016/i.eururo.2012.05.045

2. Porpiglia $F$, Bertolo $R$, Manfredi $M$, et al. Total anatomical reconstruction during robot-assisted radical prostatectomy: Implications on early recovery of urinary continence. Eur Urol 2016;69:485-95. https://doi.org/10.1016/i.eururo.2015.08.005

3. Patel VR, Abdul-Muhsin HM, Schatloff 0 , et al. Critical review of 'pentafecta' outcomes after robot-assisted laparoscopic prostatectomy in high-volume centres. BJU Int 2011;108:1007-17. https://doi.org/10.1111/i.1464-410X.2011.10521.x

4. Patel VR, Sivaraman A, Coelho RF, et al. Pentafecta: A new concept for reporting outcomes of robotassisted laparoscopic radical prostatectomy. Eur Urol 2011;59:702-7. https://doi.org/10.1016/i. eururo.2011.01.032

5. Holm HV, Fossa SD, Hedlund H, et al. Study of generic quality of life in patients operated on for postprostatectomy incontinence. Int J Urol 2013;20:889-95. https://doi.org/10.1111/iiu.12077

6. Lee DJ, Cheetham P, Badani KK. Predictors of early urinary continence after robotic prostatectomy. Can J Urol 2010;17:5200-5.

7. Novara $G$, Ficarra $V, D^{\prime}$ Elia $C$, et al. Evaluating urinary continence and preoperative predictors of urinary continence after robot-assisted laparoscopic radical prostatectomy. J Urol 2010;184:1028-33. https://doi.org/10.1016/i.juro.2010.04.069

8. Ploussard $G$, de la Taille A, Moulin M, et al. Comparisons of the perioperative, functional, and oncological outcomes after robot-assisted vs. pure extraperitoneal laparoscopic radical prostatectomy. Eur Urol 2014;65:610-9. https://doi.org/10.1016/i.eururo.2012.11.049

9. Martin AD, Nakamura LY, Nunez RN, et al. Incontinence after radical prostatectomy: A patient-centred analysis and implications for preoperative counseling. J Urol 2011;186:204-8. https://doi.org/10.1016/i. juro.2011.02.2698

10. Matsushita K, Kent MT, Vickers AJ, et al. Preoperative predictive model of recovery of urinary continence after radical prostatectomy. BJU Int 2015;116:577-83. https://doi.org/10.1111/bju.13087
11. Paparel P, Akin O, Sandhu IS, et al. Recovery of urinary continence after radical prostatectomy: Association with urethral length and urethral fibrosis measured by preoperative and postoperative endorectal magnetic resonance imaging. Eur Urol 2009;55:629-37. https://doi.org/10.1016/i.eururo.2008.08.057

12. Shikanov $S$, Desai V, Razmaria A, et al. Robotic radical prostatectomy for elderly patients: Probability of achieving continence and potency one year after surgery. J Urol 2010;183:1803-7. https://doi.org/10.1016/i.juro.2010.01.016

13. Hakimi AA, Faleck DM, Agalliu I, et al. Preoperative and intraoperative measurements of urethral length as predictors of continence after robot-assisted radical prostatectomy. J Endourol 2011;25:1025-30. https://doi.org/10.1089/end.2010.0692

14. Hamada A, Razdan S, Etafy MH, et al. Early return of continence in patients undergoing robot-assisted laparoscopic prostatectomy using modified maximal urethral length preservation technique. J Endourol 2014;28:930-8. htrps://doi.org/10.1089/end.2013.0794

15. Kojima $\mathrm{Y}$, Takahashi N, Haga N, et al. Urinary incontinence after robot-assisted radical prostatectomy: Pathophysiology and intraoperative techniques to improve surgical outcome. Int J Urol 2013;20:1052-63. https://doi.org/10.1111/iju.12214

16. von Bodman C, Matsushita K, Savage C, et al. Recovery of urinary function after radical prostatectomy: Predictors of urinary function on preoperative prostate magnetic resonance imaging. J Urol 2012;187:94550. https://doi.org/10.1016/i.juro.2011.10.143

17. Dubbelman YD, Groen J, Wildhagen MF, et al. Urodynamic quantification of decrease in sphincter function after radical prostatectomy: Relation to postoperative continence status and the effect of intensive pelvic floor muscle exercises. Neurourol Urodyn 2012;31:646-51. https://doi.org/10.1002/nau.21243

18. Coakley FV, Eberhardt $\mathrm{S}$, Kattan MW, et al. Urinary continence after radical retropubic prostatectomy: Relationship with membranous urethral length on preoperative endorectal magnetic resonance imaging. J Urol 2002;168:1032-5. https://doi.org/10.1016/S0022-5347(05)64568-5

19. Nguyen L, Jhaveri J, Tewari A. Surgical technique to overcome anatomical shortcoming: Balancing postprostatectomy continence outcomes of urethral sphincter lengths on preoperative magnetic resonance imaging. J Urol 2008;179:1907-11. https://doi.org/10.1016/i.juro.2008.01.036

20. Cameron AP, Suskind AM, Neer C, et al. Functional and anatomical differences between continent and incontinent men post radical prostatectomy on urodynamics and 3T MRI: A pilot study. Neurourol Urodyn 2015;34:527-32. https://doi.org/10.1002/nau.22616

21. Haga N, Ogawa S, Yabe M, et al. Association between postoperative pelvic anatomic features on magnetic resonance imaging and lower tract urinary symptoms affer radical prostatectomy. Urology 2014;84:642-9. https://doi.org/10.1016/i.urology.2014.04.044

22. Song C, Doo CK, Hong JH, et al. Relationship between the integrity of the pelvic floor muscles and early recovery of continence after radical prostatectomy. J Urol 2007;178:208-11. https://doi.org/10.1016/i.juro.2007.03.044

23. van der Poel HG, de Blok W, Joshi N, et al. Preservation of lateral prostatic fascia is associated with urine continence after robotic-assisted prostatectomy. Eur Urol 2009;55:892-900. https://doi.org/10.1016/i. eururo.2009.01.021

24. Kirschner-Hermanns $R$, Anding R, Stief $C G$, et al. [Imaging diagnostics of the male pelvic floor]. Urologe A 2013;52:527-32. https://doi.org/10.1007/s00120-013-3142-4

25. Mizutani $Y$, Uehara H, Fujisue $\mathrm{Y}$, et al. Urinary continence following laparoscopic radical prostatectomy: Association with postoperative membranous urethral length measured using real-ime intraoperative transrectal ultrasonography. Oncol Lett 2012;3:181-4.

26. Gerullis $H$, Georgas $E$, Quast $S$, et al. Early endoscopic detection and subsequent removal of sphincter penetrating anastomotic sutures may prevent irreversible urinary incontinence after radical prostatectomy. J Endourol 2012;26:889-94. htrps://doi.org/10.1089/end.2011.0643

27. Teber $D$, Sofikerim $M$, Ates $M$, et al. Is type 2 diabetes mellitus a predictive factor for incontinence after laparoscopic radical prostatectomy? A matched pair and multivariate analysis. J Urol 2010;183:1087-91. https://doi.org/10.1016/i.juro.2009.11.033

28. Bauer RM, Gozzi C, Hubner W, et al. Contemporary management of post-prostatectomy incontinence. Eur Urol 2011;59:985-96. https://doi.org/10.1016/i.eururo.2011.03.020

Correspondence: Dr. Hyun Moo Lee, Department of Urology, Samsung Medical Centre, Sungkyunkwan University School of Medicine, Seoul, Korea; besthm|@medimail.co.kr 